\title{
The Implication of Significant Number in Geodetic Computations: Geometric Geoid Model of FCT Abuja as a Case Study
}

\author{
Oluyori, P. D. \\ Department of Surveying and Geoinformatics \\ Nnamdi Azikiwe University Awka, Anambra State, Nigeria \\ E-mail: dareoluyori@gmail.com \\ Eteje, S. O. \\ Department of Surveying and Geoinformatics \\ Nnamdi Azikiwe University Awka, Anambra State, Nigeria \\ E-mail: eteje.sylvester@yahoo.com
}

\begin{abstract}
The position occupied by the geoid in the computation of orthometric height $(\mathrm{H})$ from GNSS observations is crucial and hence requires the geoid model parameters obtained with the application of least squares technique, be approximated to a reasonable number of significant figures in its (geoid) modelling to enable a high-resolution geometric geoid, be determined. As a result, this study presents the implication of significant number in geodetic computations using geometric geoid model of FCT, Abuja as a case study. The number of significant figures of the model parameters was varied, starting from 6 to 22 significant figures to enable the Root Mean Square Errors (RMSEs), as well as the accuracy of the model, be obtained at the varied numbers of significant figures. The obtained results show that the highest accuracy of the model is obtained if the model parameters are approximated to a reasonable number of significant figures.
\end{abstract}

Keywords: geometric, geoid, height, significant, figure, geodetic, computation, modelling

DOI: $10.7176 /$ JSTR/6-08-09

\section{Introduction}

The importance of geoid has resulted in its listing or opined by Dodo and Idowu (2010) and others as a requirement of National Geospatial Data Infrastructure (NGDI) and therefore involving geodetic computations using space technique of GPS/GNSS. Geodetic computations require evaluation of significant numbers for acceptable and meaningful results to be obtained.

The study involves the computations of geoid undulation $(\mathrm{N})$ by geometric geoid method. Oluyori (2019) suggest or opined the geoid to be essentially an equipotential and continuous surface highly consistent for vertical reference surface for heights in the metric unit and ensures height continuity across borders.

Significant numbers/figures most importantly give us useful information about the accuracy of measurements and computations made and recorded i.e. resolution. For example, if a measurement of 1000 has one significant figure/digit (s.f /d) while 1000.0 has five s.f because the .0 has something interesting to tell us about accuracy being made to the tenth or the decimal means that measurement was made to the nearest unit. In other words, significant figures can be viewed as a number contributing something to the precision of the number. Or by calculations introduce more precision than the given or original data, e.g. $\mathrm{N}=22.787 \mathrm{~m}$ and by calculation $\mathrm{N}=22.78746 \mathrm{~m}$. In geometric geoid modelling, the model parameters are computed using the least squares technique. Most of these parameters usually contain a large number of zeros resulting in a small number of significant figures. As a result, they are usually approximated to zero without considering the effect of ignoring the significant numbers they contain, in the accuracy of the model. Consequently, this study presents the implication of significant number in geodetic computations using geometric geoid model of FCT, Abuja as a case study.

\subsection{Mathematical Models}

Consider numbers (small or big) that can be multiplied, divided, added, subtracted and may be written as exponentials:- 


$$
a_{o}=b_{o} \times 10^{c}
$$

Then similarly

$$
a_{1}=b_{1} \times 10^{c 1}
$$

The multiplication is

$$
a_{o} a_{1}=b_{0} b_{1} \times 10^{c+c 1}
$$

Division is given by

$$
a_{o} / a_{1}=\left(b_{o} / b_{1}\right) \times 10^{c-c 1}
$$

For addition and subtraction, we have

$$
a_{o} \pm a_{1}=\left(b_{o} \pm b_{1}\right) \times 10^{c \pm c 1}
$$

In performing calculations, significant numbers could be lost sometimes and this is expected due to measurement uncertainty associated. To typify the numbers and their various calculations, the flowchart, as well as Figure 1, is explanatory.

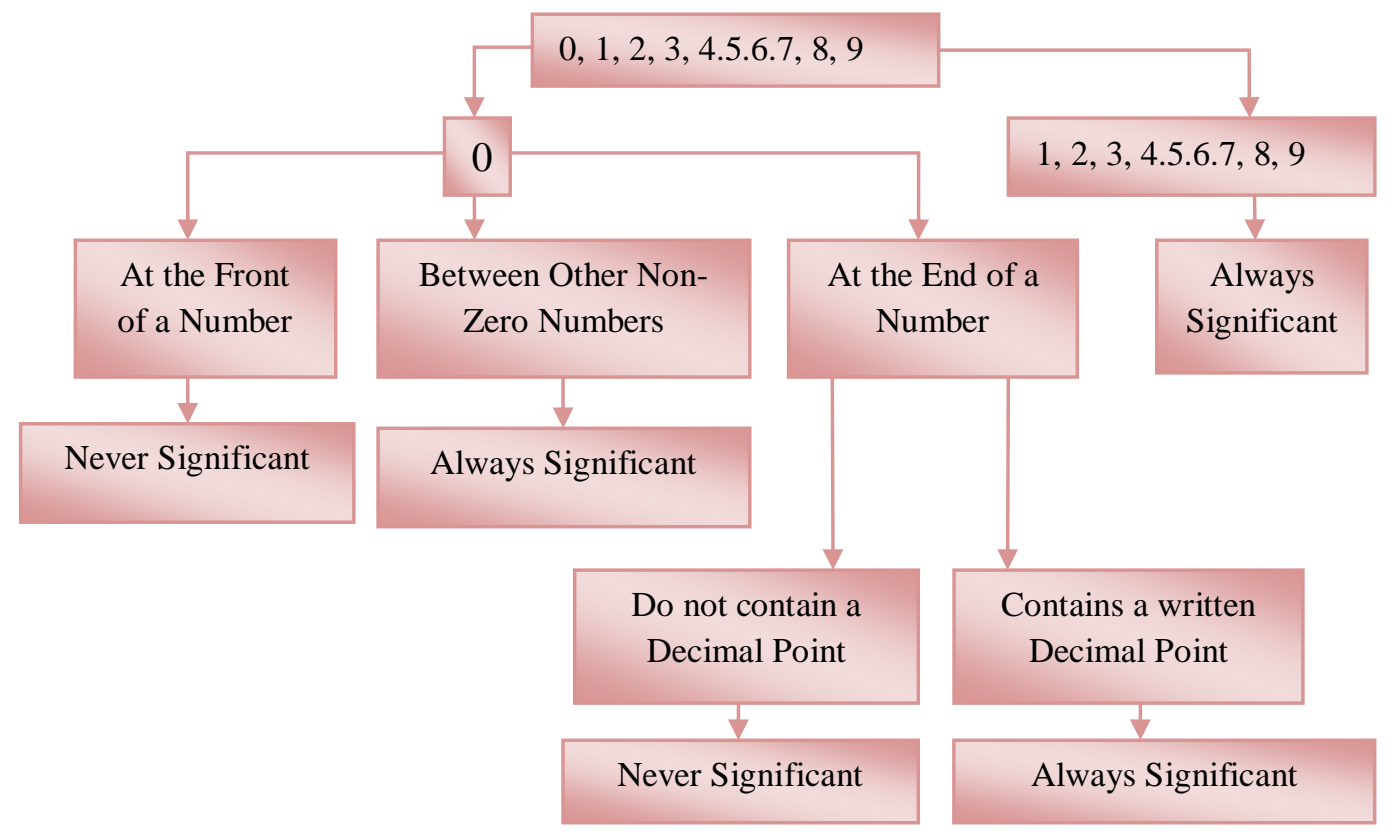

Figure 1: Flow Chart of Model

Source: Michael (2016)

For a number to carry meaning in any measurement resolution, the number of significant figures and digits must be known. To do this, numbers are classified into:

i. All non-zero digits are significant e.g. 1,2,3,4,5,6,7,8,9.

ii. Zeros between non-zero digits are significant e.g. 102.7005 , etc.

iii. Leading zeros are never significant e.g. 002, 008767, 000000034.

iv. In a number with or without a decimal point, trailing zeros (those to the right of last non-zero digit are significant, provided they are justified by the precision of derivation: 389,000; 2002000; 5.400 . or as summarized and detailed in https://www.usna.edu.

The final results of geodetic computations in this study or any such other must contain the same number of the significant figures as the original number with the fewest significant figures as opined by https://courses.lumenlearning.con. It is opined by ESA (2014) that in fact "the number should be given in $2-3$ effective digits" and further that the decimal rule that ignores significant digits is never acceptable or cannot work.

These specifications may be put graphically under rules (S or NS) shown in Figure 2. 


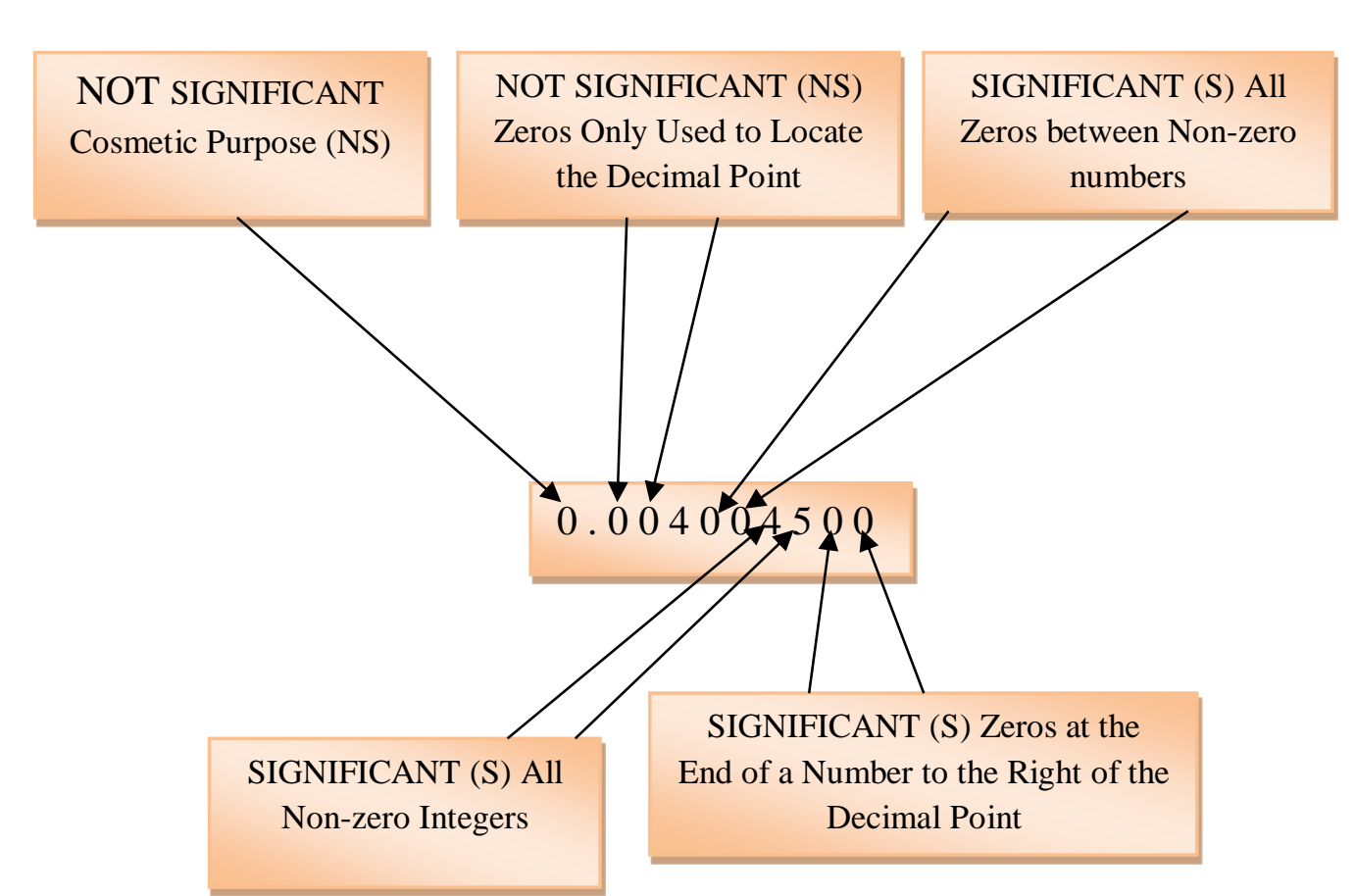

Figure 2: Significant or Not Figures Rules Source https://getstartedinscience.weedly.com

Details can also be found in standard mathematics textbooks.

The model considered for FCT surface fitting in the case study is the multi-quadratic model (nine parameters) given by Sanlioglu et al. (2009) and Oluyori et al. (2018) as

$$
N=a_{0}+a_{1} x+a_{2} y+a_{3} x^{2}+a_{4} y^{2}+a_{5} x y+a_{6} x^{2} y+a_{7} x y^{2}+a_{8} x^{2} y^{2}
$$

Where $x$ and $y$ are the DGPS known coordinates, $\mathrm{a}_{0}, \mathrm{a}_{1}, \mathrm{a}_{2} \ldots$ are the parameters to be determined and $N$ is the geoid undulation.

\subsection{Observation Equations (Least Squares Adjustment)}

Observation equations are written for the parametric model as one equation for each observation and generally as given in Ono et al. (2014),

$$
A X=L
$$

Where $A$ is a design matrix, $X$ is the coefficients and $L$ is the measurements.

When the number of measurements $(m)$ is greater than the number of unknowns $(n)(m>n)$, then we have redundant observations, as well as degrees of freedom (d.o.f) requiring least squares adjustments solutions. When there are redundant equations, the system is said to be over-determined: $A$ is not a square matrix but $A^{T} \mathrm{~A}$ is a square matrix, according to Ono et al. (2014),

$$
A^{T} A X=A^{T} L
$$

Let $N=A^{T} A$ and $n=A^{T} L$

Then $X=N^{-1} n$. This implies that

$$
N X=A^{T} L
$$

For unit weight, the solution is given as

$$
X=\left(A^{T} A\right)^{-1}\left(A^{T} L\right)
$$

Here, the unit weight is due to equal reliability of observations. 
Where,

$\mathrm{A}=$ Design matrix.

$\mathrm{X}=$ Vector of unknown parameters/coefficients.

$\mathrm{P}=$ Weight matrix $=1$

$\mathrm{L}=$ Geoid undulations $(\mathrm{N}=\mathrm{h}-\mathrm{H})$.

To use the least squares solution, first solve for the values of the polynomial constants $\left(a_{0}, a_{1, \ldots}, a_{n}\right)$ using the computed geoidal undulation $(\mathrm{N})$ values and the known northing ( $y$ or $\mathrm{n})$ and easting $(x$ or e) coordinates of the observation/control points. The computed polynomial constants, and the differences between the centroid and the observation points' coordinates, are substituted into the polynomial model (multi-quadratic) to obtain the model geoid heights of points in the study area.

\subsection{Root Mean Square Error}

The Root Mean Square Error, RMSE index for the computation of the geometric geoid model accuracy as given by Eteje and Oduyebo (2018) is

$$
R M S E= \pm \sqrt{\frac{V^{T} V}{n}}
$$

Where,

$$
\begin{aligned}
& V=N_{K N O W N}-N_{M O D E L} \text { (Residual) } \\
& N_{K N O W N}=\text { Known geoid height of point } \\
& N_{M O D E L}=\text { Model geoid height of point } \\
& \mathrm{n}=\text { Number of points }
\end{aligned}
$$

\section{Methodology}

The methodology adopted for the derivation of the geoid heights used to determine the geometric geoid model of FCT, Abuja, Nigeria, given in Table 1, is detailed in Oluyori et al. (2019).

Table 1: Coordinates and Geoid Heights of Points

\begin{tabular}{|c|c|c|c|}
\hline $\begin{array}{c}\text { Control } \\
\text { Points }\end{array}$ & Easting (e) $\mathbf{( m )}$ & $\begin{array}{c}\text { Northing }(\mathbf{n}) \mathbf{y} \\
(\mathbf{m})\end{array}$ & $\begin{array}{c}\text { Computed } \\
\text { Geoid Heights } \\
(\mathbf{m})\end{array}$ \\
\hline FCC11S & 331888.114 & 998442.043 & 23.949 \\
\hline FCT260P & 255881.175 & 993666.807 & 22.787 \\
\hline FCT103P & 340639.766 & 998375.578 & 24.278 \\
\hline FCT12P & 333743.992 & 1008308.730 & 24.485 \\
\hline FCT19P & 337452.408 & 996344.691 & 24.180 \\
\hline FCT2107S & 308926.908 & 989748.256 & 24.187 \\
\hline FCT2168S & 310554.927 & 1009739.930 & 24.183 \\
\hline FCT24P & 322719.776 & 1001884.850 & 24.276 \\
\hline FCT276P & 351983.716 & 1025998.314 & 24.251 \\
\hline FCT4154S & 329953.882 & 1003831.280 & 24.323 \\
\hline FCT4159S & 326124.422 & 1003742.860 & 24.004 \\
\hline FCT66P & 299148.035 & 998114.283 & 24.440 \\
\hline FCT9P & 329821.512 & 1007612.091 & 24.128 \\
\hline FCT35P & 322183.380 & 992926.363 & 23.951 \\
\hline FCT57P & 303234.270 & 992916.402 & 24.350 \\
\hline FCT4028S & 330164.634 & 1001388.240 & 24.012 \\
\hline FCT53P & 308943.361 & 993406.773 & 24.402 \\
\hline FCT4652S & 329441.767 & 997474.808 & 25.395 \\
\hline FCT162P & 270791.291 & 934625.533 & 23.775 \\
\hline FCT130P & 330982.584 & 952889.869 & 24.195 \\
\hline FCT2327S & 282526.612 & 973821.470 & 24.789 \\
\hline FCT2652S & 271370.273 & 945385.429 & 24.505 \\
\hline FCT2656S & 272644.591 & 941062.460 & 24.067 \\
\hline FCT83P & 332954.205 & 987231.606 & 23.804 \\
\hline XP382 & 284074.729 & 983364.863 & 23.949 \\
\hline & & & \\
\hline
\end{tabular}

87 I P a g e 
The model parameters were computed using the least squares method, as well as equation (10). The least squares model in matrix notation used for the computation of the model parameters is,

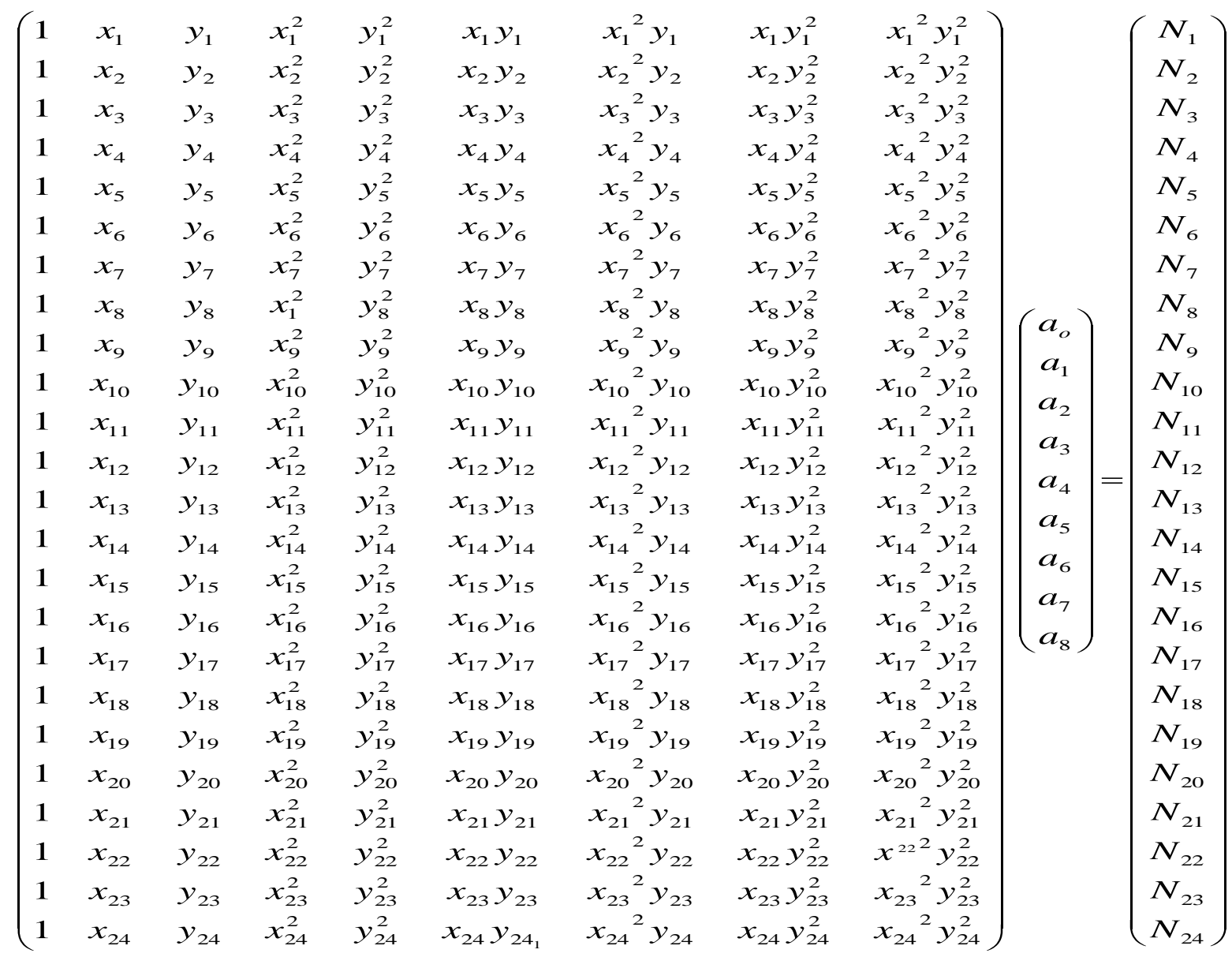

The computed model parameters using the multi-quadratic surface, are given in matrix form as

$$
X=\left(\begin{array}{l}
a_{o} \\
a_{1} \\
a_{2} \\
a_{3} \\
a_{4} \\
a_{5} \\
a_{6} \\
a_{7} \\
a_{8}
\end{array}\right)=\left(\begin{array}{c}
24.2248901210000000000 \\
-0.00002409340580587179 \\
-0.00008013620770038382 \\
0.00000000009699046795 \\
0.00000000370280953876 \\
0.00000001166702184889 \\
-0.00000000000021600943 \\
-0.00000000000045716237 \\
0.00000000000000000886
\end{array}\right)
$$

The computed model parameters were substituted into the multi-quadratic surface, as well as equation (6) at varying numbers of significant figures, starting with 6 significant figures to compute the model geoid heights of the points. The commencement of the experiment using 6 significant figures was as a result of the number of zeros before the first significant figure in the model parameter- $a_{1}$. If any significant figure less than 6 was used, the computation result would have been the corresponding model parameters- $a_{o}$ value and would have also been constant for all the points. The numbers of significant figures used in this study ranged from 6 to 22 as the computation started with 6 significant figures in the model parameter- $a_{1}$ and ended with the 3 significant figures in the model parameter- $a_{8}$. The 
computation was carried out using a Microsoft Excel program developed during the determination of the local geometric geoid model of FCT, Abuja. The root mean square error (RMSE) of the model was also computed at the varying numbers of significant figures to obtain the accuracy of the model. The computation was done by comparing the model geoid heights of the points at the varying numbers of significant figures with their respective computed geoid heights to obtain the residuals. The obtained residuals and the total number of points were applied in equation (11) to obtain the RMSE, as well as the accuracy of the model at the varying numbers of significant figures.

\section{Results Presentation and Analysis}

Table 2 presents the computed RMSE of the model at the varying numbers of significant figures. It was done to obtain the accuracy of the model at the varying numbers of significant figures. Also, Figure 3 presents the plot of the computed model RMSE at the varying numbers of significant figures. It was done to show graphically, the accuracy of the model at the varying numbers of significant figures. Here, the accuracy of the model varies inversely to the height of the plotted RMSE. It can be seen in Table 2 that the RMSE of the model from 6 to 22 significant figures are respectively $0.441 \mathrm{~m}, 2.421 \mathrm{~m}, 2.463 \mathrm{~m}$, $2.509 \mathrm{~m}, 5.743 \mathrm{~m}, 9.373 \mathrm{~m}, 10.522 \mathrm{~m}, 10.637 \mathrm{~m}, 10.649 \mathrm{~m}, 11.074 \mathrm{~m}, 13.279 \mathrm{~m}, 13.734 \mathrm{~m}, 13.738 \mathrm{~m}$, $13.740 \mathrm{~m}, 1.338 \mathrm{~m}, 0.144 \mathrm{~m}$ and $0.110 \mathrm{~m}$. At 6 significant figures, the model geoid height of the points was constant for all the points and the value was $24.225 \mathrm{~m}$. It was as a result of the number of significant figures of the model parameters- $a_{1}$ and $a_{2}$ that start from 7 significant figures relative to the model parameter- $a_{o}$. Obtaining a constant geoid height for all the points is not possible and it implies that in geometric geoid modelling when there are a large number of zeros appearing before a significant figure in the other computed parameters, the model parameter- $a_{o}$ should not be approximated to a significant figure equal the number of zeros before the significant figures in the other model parameters. The accuracy of the model from 7 to 19 significant figures ranges from $2.421 \mathrm{~m}$ to $13.740 \mathrm{~m}$. Here, as the number of zeros (not significant) in the model parameters increases relatively with an increase in the numbers of significant figures from 7 to 19, the computed values of the RMSE increase. It implies that the larger the number of significant figures ignored as a result of a large number of zero digits, the less the accuracy of the model. It can also be seen in Table 2 that from 20 to 22 significant figures, the respective computed values of the RMSE of the model are $1.338 \mathrm{~m}, 0.144 \mathrm{~m}$ and $0.110 \mathrm{~m}$. They also correspond to the 3 significant figures of the model parameter- $a_{8}$. This also implies that in geometric geoid modelling, the highest accuracy of the model is obtained if the model parameters are approximated to a reasonable number of significant figures. It can again be seen in Figure 3 that the smallest bar of the plotted RMSE, is obtained at 22 significant figures. This again implies that the accuracy of the model is highest when the model parameters are approximated to a reasonable number of significant figures.

Table 2: Computed RMS Errors at Varying Numbers of Significant Figures

\begin{tabular}{|c|c|c|c|c|c|c|}
\hline & $\begin{array}{c}6 \\
\begin{array}{c}\text { Significant } \\
\text { Figure }\end{array} \\
\end{array}$ & $\begin{array}{c}7 \\
\text { Significant } \\
\text { Figure } \\
\end{array}$ & $\begin{array}{c}8 \\
\begin{array}{c}\text { Significant } \\
\text { Figure }\end{array} \\
\end{array}$ & $\begin{array}{c}9 \\
\text { Significant } \\
\text { Figure } \\
\end{array}$ & $\begin{array}{c}10 \\
\text { Significant } \\
\text { Figure } \\
\end{array}$ & $\begin{array}{c}11 \\
\text { Significant } \\
\text { Figure } \\
\end{array}$ \\
\hline \multirow[t]{2}{*}{ RMSE (m) } & 0.441 & 2.421 & 2.463 & 2.509 & 5.743 & 9.373 \\
\hline & $\begin{array}{c}12 \\
\begin{array}{c}\text { Significant } \\
\text { Figure }\end{array} \\
\end{array}$ & $\begin{array}{c}13 \\
\text { Significant } \\
\text { Figure } \\
\end{array}$ & $\begin{array}{c}14 \\
\text { Significant } \\
\text { Figure } \\
\end{array}$ & $\begin{array}{c}15 \\
\text { Significant } \\
\text { Figure } \\
\end{array}$ & $\begin{array}{c}16 \\
\text { Significant } \\
\text { Figure }\end{array}$ & $\begin{array}{c}17 \\
\text { Significant } \\
\text { Figure }\end{array}$ \\
\hline \multirow[t]{2}{*}{ RMSE (m) } & 10.522 & 10.637 & 10.649 & 11.074 & 13.279 & 13.734 \\
\hline & $\begin{array}{c}18 \\
\begin{array}{c}\text { Significant } \\
\text { Figure }\end{array} \\
\end{array}$ & $\begin{array}{c}19 \\
\text { Significant } \\
\text { Figure } \\
\end{array}$ & $\begin{array}{c}20 \\
\text { Significant } \\
\text { Figure } \\
\end{array}$ & $\begin{array}{c}21 \\
\text { Significant } \\
\text { Figure } \\
\end{array}$ & $\begin{array}{c}22 \\
\text { Significant } \\
\text { Figure } \\
\end{array}$ & \\
\hline RMSE (m) & 13.738 & 13.740 & 1.338 & 0.144 & 0.110 & \\
\hline
\end{tabular}




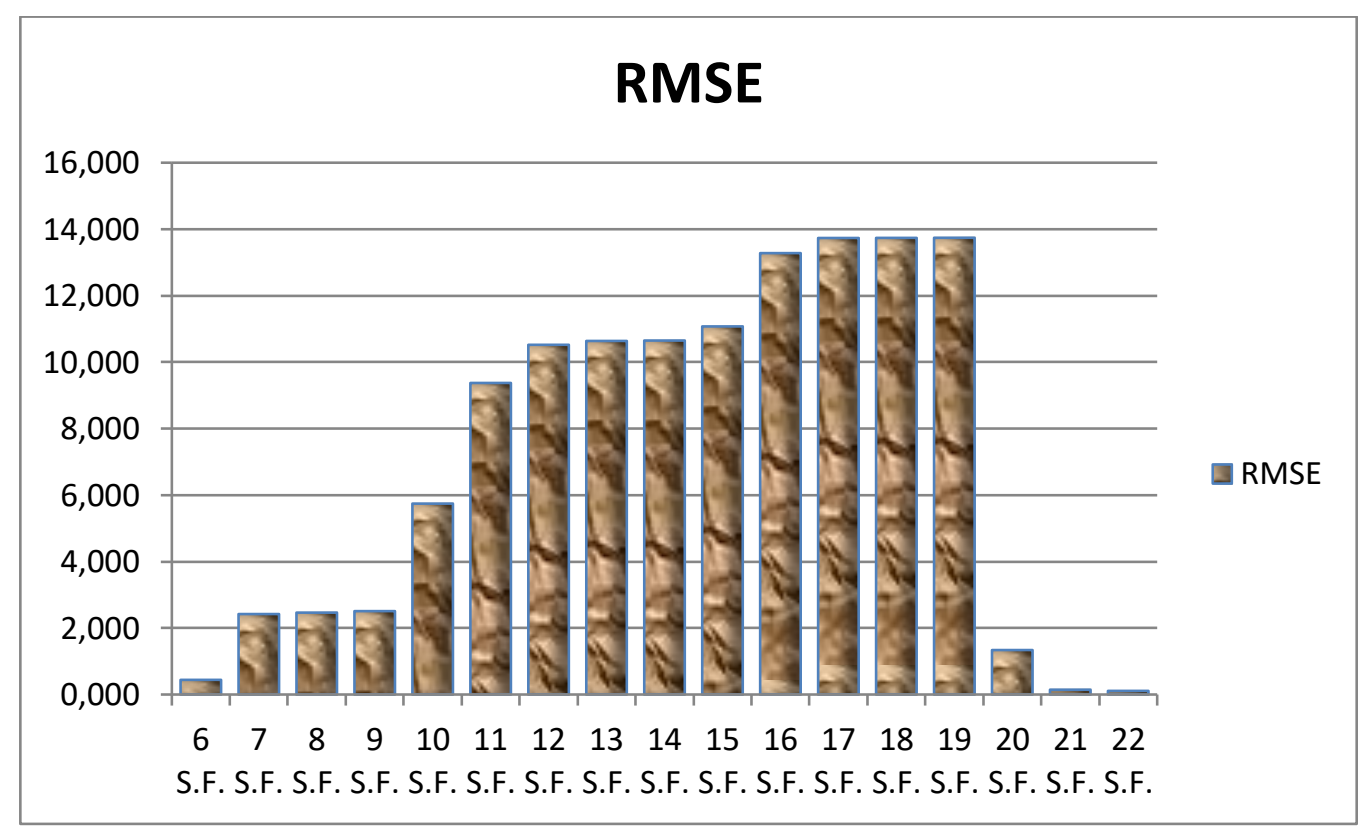

Figure 3: Computed Geoid Model RMS Errors at Varying Numbers of Significant Figures

\section{Conclusion}

In conclusion, the study has presented the implication of significant figures in geodetic computations, as well as geometric geoid modelling by varying the numbers of significant figures of the geometric geoid model parameters, computing the RMSE, as well as the accuracy of the model and comparing the computed accuracy at the varied numbers of significant figures. The results of the study have shown that the larger the number of significant figures ignored as a result of a large number of zero digits, the less the accuracy of the model. The study has also revealed that in geometric geoid modelling, the highest accuracy of the model is obtained if the model parameters are approximated to a reasonable number of significant figures.

\section{References}

Dodo, J. and Idowu, T. (2010). A framework for the Implementation of the Global Navigation Satellite System (GNSS) in Nigeria, Proceedings of the Nigerian Union of Planetary and Radio Sciences (NUPRS) Conference 2010.

ESA (2014). European Association of Science Editors, EASE Guidelines for Authors and Translators of Scientific Articles.

Eteje, S. O. and Oduyebo, O. F. (2018). Local Geometric Geoid Models Parameters and Accuracy Determination Using Least Squares Technique. International Journal of Innovative Research and Development, 7(7), 251-257. DOI: http://dx.doi.org/10.24940/ijird/2018/v7/i7/JUL18098.

Michael, S. (2016). Significant Digits and Engineering Units in https://www.allaboutcircuits.com

Oluyori, P. D. (2019). Modelling of Orthometric Heights from Multi-Networks of GNSS/Precise Levelling in Federal Capital Territory, Abuja, Nigeria. Unpublished PhD Dissertation of the Department of Surveying and Geoinformatics, Nnamdi Azikiwe University, Awka.

Oluyori, P. D., Ono, M. N. and Eteje, S. O. (2018). Computations of Geoid Undulation from Comparison of GNSS/Levelling with EGM2008 for Geodetic Applications. International Journal of Scientific and Research Publications (IJSRP), 8(10), 235-241. DOI: http://dx.doi.org/10.29322/IJSRP.8.10.2018.p8230.

Ono, M. N. (2009). On Problems of Coordinates, Coordinate Systems and Transformation Parameters in Local Map Production, Updates and Revisions in Nigeria, FIG Working Week, Eilat, Israel. 
Ono, M. N., Agbo, J. A., Ijioma, D. I. and Chubado, M. (2014): Establishment of Baseline Data for Monitoring of Deformation of Murtala Mohammed Bridge (MMB) Lokoja Kogi State, Using GPS. International Journal of Science and Technology, 4(5), 86-92.

Sanlioglu, I., Maras, S. S. and Uysal, F. (2009). Determination of Orthometric Heights with RealTime Kinematic Surveying, Konya Sample, FIG Working Week. 